\title{
Evaluating Poplar Leaf Extract Concentration on Potential Plant Pathogens
}

\author{
Jalaj Saxena $^{1 *}$, Vijay Vardhan Pandey ${ }^{1}$ and Reenu Sisodia ${ }^{2}$
}

${ }^{1}$ Forest Pathology Division, Forest Research Institute, Dehradun, 248006, Uttrakhand, India

${ }^{2}$ Department of Forestry, Dr. B.R. Ambedkar University, Agra, 282002, Uttar Pradesh, India

*Corresponding author

\begin{tabular}{|c|c|}
\hline & A B S T R A C T \\
\hline & Today, Poplar clones, being raised as monocultures, are prone to attack of a \\
\hline Keywords & large number of fungal pathogens. These pathogens are in vitro cultured for \\
\hline $\begin{array}{l}\text { Poplar, Extract, } \\
\text { Pathogen, Growth. }\end{array}$ & $\begin{array}{l}\text { varied studies. It is believed that natural media (vegetable and plant extract } \\
\text { host decoction), stimulates growth and sporulation of a fungus. Therefore, }\end{array}$ \\
\hline Article Info & the present study was conducted to evaluate the influence of different \\
\hline $\begin{array}{l}\text { Accepted: } \\
26 \text { August } 2017 \\
\text { Available Online: } \\
10 \text { September } 2017\end{array}$ & $\begin{array}{l}\text { Nine isolates three of each Bipolaris sp., Curvularia sp. and Sclerotium } \\
\text { rolfsii were taken for experimentation. All these pathogenic fungi had } \\
\text { better growth in leaf extract medium than without it but fungal growth was }\end{array}$ \\
\hline
\end{tabular}

\section{Introduction}

Poplar belongs to the family Salicaeceae, order Salicales and group Amentiflorae (Dickmann and Stuart, 1983; Eckenwalder, 1996). There are 35 species of poplar currently recognized in the world; out of those, 6 Populus species are indigenous to India- $P$. alba, $P$. ciliata, $P$. euphratica, $P$. gamblei, $P$. glauca and $P$. laurifolia, and during past many clones of exotic species of poplar ( $P$. deltoides and $P$. xuramericana) have been introduced in India in area between $28^{\circ}$ to $31^{\circ} \mathrm{N}$. Poplar have very specialized climatic and edaphic requirements, this is the reason which restrict their cultivation in India (Tewari, 1993).

In India, poplars ( $P$. deltoides) are eminently suited for agroforestry because of its fast growth, straight- growing stem, short rotation, quality wood production and less adverse effect on agriculture crops (Bangarwa, 2008) and are being grown in Uttar Pradesh, Uttarakhand, Punjab, Haryana and Jammu and Kashmir (Singh et al., 1999). P. deltoides enters in dormancy during winter and become leafless, and let the sunlight to pass through it, for the companion crops, therefore, suited well to companion crops. In the interspace of poplar plantations, several seasonal crops are cultivated for enhancement of overall productivity of the land and generation of supplementary income (Jaiswal et al., 1993; Singh et al., 1993; Jain and Singh, 1999).

The ease with which most materials can be vegetatively propagated is one of poplar's 
premier assets. So that in India, poplar is grown under forestry programmes as clonal plantations i.e. from a single plant infinite number of plants can be develop to ensure the genetic superiority for better growth and superior wood quality (Pande and Dhiman, 2010). Meanwhile, favoured by their simple clonal propagation, relatively rapid growth rate and considerably small genome size among woody species, they are one of the major model plants used in both scientific and industrial research (Bradshaw et al., 2000; Polle and Douglas, 2010). By taking cuttings from a single tree, infinite number of genetically identical trees can be produced better known as clones (Charlton et al., 2007). Several promising clones of $P$. deltoides namely; G, D, Sc, I, IC, PL, St, L, WSL, Wimco series, etc., have been identified and, subsequently, planted in farm/agro forestry systems throughout Punjab, Haryana, Tarai region of Uttrakhand, western part of Uttar Pradesh, some parts of Bihar, West Bengal and Assam (Mishra et al., 2010; Dhiman and Gandhi, 2012).

About 90 percent of the poplar plantations in India are of the clones G-48, D-121, S7C15 and G-3 (Kumar et al., 1999). The clonal forestry in India represents a very narrow genetic base of the planting material. Clones, being raised as monocultures, are thus prone to a large number of fungal pathogens and disease outbreaks (Singh et al., 2012). Disease in poplar may occur in any stage from the time of planting of cutting in beds till they are extracted as entire transplant (ETPs) for field planting as well as in plantation. Large numbers of foliage diseases were recorded in poplar nurseries. Fungi causing leaf spots and blights are Alternaria alternata, Bipolaris sp., Cercospora populina, Cladosporium humile, Corticium salmonicolor, Curvularia sp., Drechslera maydis, Fusarium solani, Pollaccia sp., Phoma sp., Phyllosticta adjuncta, Rhizoctonia microsclerotia, Sclerotium rolfsii and Septoria sp. (Pandey and Khan, 1992; Singh et al., 2012). Poplar also suffers from root rot namely; white root rot, Ganoderma root rot, Rhizoctonia root rot and Fusarium root rot (Singh et al., 1983). Fusarium is one of the important pathogens that cause mortality of planted cutting.

Sub culturing in forest pathology is to grow and sustain a pathogen's sample suitable for experimentation and tests. Sub culturing prolongs the lifespan of pathogens, allowing for long-term maintenance and observation of the culture. On the other hand, repeated sub culturing in axenic media cause the loss of sporulation in pathogen which is associated with the loss of virulence. Zhao and Shamoun (2006) suggested that nature of a culture medium has great role to play in the growth, sporulation and conidial discharge of Valdensinia heterodoxa. It is believed that natural media (vegetable and plant extract host decoction) stimulates the growth of fungus (Patil and Rao, 2003). Therefore, periodic mixing of host extract in the medium during sub culturing is one of the strategies to revive the fungal characteristics. Probably, the complex of constituents of the host extract offers some nutrients that, otherwise, are lacking in the synthetic medium. Therefore, the present study was conducted to evaluate the influence of different concentration of host ( $P$. deltoides) leaf extract media on mycelial growth of Bipolaris sp., Curvularia sp. and Sclerotium rolfsii.

\section{Materials and Methods}

\section{Collection of Fungal Isolates}

Nine isolates three of each Bipolaris sp., Curvularia sp. and Sclerotium rolfsii were taken from Forest Pathology Division, Forest Research Institute, Dehradun for experimentation (Table1 to 3). 


\section{Preparation of Leaf Extract Medium}

Leaves were collected from $P$. deltoides, weighted $5,10,15,20,25 \mathrm{~g}$ for making 5,10 , $15,20,25 \%$ leaf extract media, respectively. After weighing, leaves of poplar were washed thoroughly in tap water and sterilized distilled water and boiled in $100 \mathrm{ml}$ distilled water and then filtered to separate the leaf extract from the leaves. Finally make up the leaf extract to $100 \mathrm{ml}$ by adding distilled water because during the process of making leaf extract, some water evaporates. Then, $1.2 \mathrm{gm}$. PDB was added to $50 \mathrm{ml}$ leaf extract of different concentrations $(5 \% ; 10 \% ; 15 \% ; 20 \%$ and $25 \%$ ), stirred vigorously and autoclave it to obtain natural leaf extract medium.

PDB (Potato Dextrose Broth) is liquid medium used as control medium for the study of fungi. Ready-made media of PDB was used $24 \mathrm{~g} / 1000 \mathrm{ml}$ of distilled water.

\section{Inoculation}

Five mm disc of 7 days old mother culture of different fungal isolates were transferred into the conical flasks of $100 \mathrm{ml}$ volume containing $50 \mathrm{ml}$ media. Then, it was incubated at $22^{\circ} \pm 1^{\circ} \mathrm{C}$ in BOD incubator for 21 days.

\section{Growth Measurement}

Growth parameters Dry weight, Sclerotia Initation, Maturation and Sclerotia Count (in case of sclerotia forming fungus Sclerotium rolfsii) were used for the measurement of the growth.

\section{Statistical Analysis}

Data was analyzed with the GENSTAT 5 Release 3.22. Two way analyses were used for growth. Treatments means were compared at $5 \%$ level of significance.

\section{Results and Discussion}

Present study deal with effect of poplar leaf extract on the growth of three fungi namely, Bipolaris sp., Curvularia sp. and Sclerotium rolfsii. Following trends were found:

Table 4 depicted the pattern of growth of Bipolaris sp., Curvularia sp. and Sclerotium rolfsii at different concentrations (5-25\%) of poplar leaf extract. It was found that all fungi exhibited growth only at lower concentration of leaf extract tested, i.e., 5 and $10 \%$. While no growth was recorded at higher concentrations of leaf extract (15-25\%). Further, it was noticed that isolates of Bipolaris and Curvularia exhibited growth till $10 \%$ leaf extract concentration (Fig.1, 2). In contrasting, Sclerotium rolfsii isolates showed no growth at even $10 \%$ poplar leaf extract concentration (Fig.3).

\section{Dry Mycelium Weight}

The growth of Bipolaris sp. isolates showed differential pattern on different poplar leaf extract concentrations. Irrespective of leaf extract concentrations, isolate no. B-59 showed significant and maximum dry mycelium weight $(0.27 \mathrm{~g})$ while, minimum growth $(0.12 \mathrm{~g})$ was recorded for the isolate no. B-22. Isolates showed significantly more and maximum growth at $10 \%$ leaf extract concentrations. Further, the growth was significantly minimum on control (Table 5.).

When interactions between fungal isolate and concentrations $\left(I^{*} \mathrm{C}\right)$ were studied, it was observed that all isolates attained growth only at lower concentrations (5 and $10 \%$ ). Isolate no. B-59 showed maximum and significantly more growth at $10 \%$ concentration $(0.60 \mathrm{~g})$. Minimum dry mycelium weight $(0.31 \mathrm{~g})$ was recorded by isolate no. B-22 on control which was at par with isolate no. B- 25 on same medium $(0.31 \mathrm{~g})$. Barring isolate no. B-59 
$(0.50 \mathrm{~g})$ at $5 \%$ concentration, all the isolates had significantly more dry mycelium weight than control (Table 5). While, dry mycelium weight of isolate no. B-59 was significantly higher on control than $5 \%$ concentration (0.53 and $0.50 \mathrm{~g}$, respectively).

Irrespective of different poplar leaf extract concentrations tested, it was observed that isolate no. C-40 $(0.29 \mathrm{~g})$ had maximum dry mycelium weight (Table 6). While, minimum dry mycelium weight was recorded for the isolate no. C-29 (0.23g). Highest dry mycelium weight of the Curvularia sp. isolates were recorded at $10 \%$ leaf extract concentration. No growth was recorded at 15 concentrations, i.e., none of the isolate could grow at $15-25 \%$ leaf extract concentration. Second to it, significantly low dry mycelium weight was recorded at control $(0.35 \mathrm{~g})$.

Table.1 Details of the Bipolaris sp. isolates

\begin{tabular}{|l|l|l|}
\hline Isolate No. & Place & Clone \\
\hline B25 & Baghwala,Rudrapur & G-3 \\
\hline B58 & Baghwala,Rudrapur & G-3 \\
\hline B59 & Wimco nursery, Saharanpur & W-39 \\
\hline
\end{tabular}

Table.2 Details of the Curvularia sp. isolates

\begin{tabular}{|l|l|l|}
\hline Isolate No. & Place & Clone \\
\hline C29 & Jawahar Nagar, Rudrapur & WSL-39 \\
\hline C35 & Bagwala,Rudrapur & G-48 \\
\hline C40 & Bagwala,Rudrapur & G-48 \\
\hline
\end{tabular}

Table.3 Details of the Sclerotium rolfsii isolates

\begin{tabular}{|l|l|l|}
\hline Isolate No. & Place & Clone \\
\hline S21 & Baghwala,Rudrapur & Udai \\
\hline S97 & Baghwala,Rudrapur & W-108 \\
\hline S104 & Baghwala,Rudrapur & W -108 \\
\hline
\end{tabular}

Table.4 Effect of different concentrations of poplar leaf extract on the growth of Bipolaris sp., Curvularia sp. and Sclerotium rolfsii

\begin{tabular}{|l|l|l|l|l|l|l|}
\hline \multirow{2}{*}{ Isolate No. } & \multicolumn{7}{l}{ Plant extract (\%)/Growth } & $\mathbf{2 0}$ & $\mathbf{2 5}$ \\
\cline { 2 - 7 } & $\mathbf{0}$ (Control) & $\mathbf{5}$ & $\mathbf{1 0}$ & $\mathbf{1 5}$ & $\mathbf{2 0}$ & - \\
\hline B-22 & + & + & + & - & - & - \\
\hline B-25 & + & + & + & - & - & - \\
\hline B-59 & + & + & + & - & - & - \\
\hline C-29 & + & + & + & - & - & - \\
\hline C-35 & + & + & + & - & - & - \\
\hline C-40 & + & + & + & - & - & - \\
\hline S-21 & + & + & - & - & - & - \\
\hline S-97 & + & + & - & - & - & - \\
\hline S-104 & + & + & - & - & - & - \\
\hline
\end{tabular}

$+=$ Normal Growth, $-=$ No Growth 
Table.5 Effect of different concentrations of poplar leaf extract on the growth of Bipolaris sp.

\begin{tabular}{|l|l|l|l|l|l|l|l|}
\hline \multirow{2}{*}{$\begin{array}{l}\text { Isolate } \\
\text { No. }\end{array}$} & \multicolumn{6}{l}{ Plant extract (\%)/Dry mycelium weight (g) } & \multirow{2}{*}{ Mean } \\
\cline { 2 - 8 } & Control (0) & $\mathbf{5}$ & $\mathbf{1 0}$ & $\mathbf{1 5}$ & $\mathbf{2 0}$ & $\mathbf{2 5}$ & \\
\hline B-22 & 0.31 & 0.35 & 0.42 & 0.00 & 0.00 & 0.00 & 0.12 \\
\hline B-25 & 0.31 & 0.35 & 0.44 & 0.00 & 0.00 & 0.00 & 0.18 \\
\hline B-59 & 0.53 & 0.50 & 0.60 & 0.00 & 0.00 & 0.00 & 0.27 \\
\hline Mean & 0.38 & 0.40 & 0.49 & 0.00 & 0.00 & 0.00 & \\
\hline & Isolate & Concentration & \multicolumn{2}{l}{ Interaction (I*C) } \\
\hline SEM & 0.003 & 0.004 & 0.006 & \\
\hline CD (5\%) & 0.01 & 0.01 & 0.02 & \\
\hline
\end{tabular}

Table.6 Effect of different concentrations of poplar leaf extract on the growth of Curvularia sp.

\begin{tabular}{|l|l|l|l|l|l|l|l|}
\hline \multirow{2}{*}{$\begin{array}{l}\text { Isolate } \\
\text { No. }\end{array}$} & \multicolumn{6}{l}{ Plant extract (\%)/Dry mycelium weight (g) } & \multirow{2}{*}{ Mean } \\
\cline { 2 - 8 } & Control (0) & $\mathbf{5}$ & $\mathbf{1 0}$ & $\mathbf{1 5}$ & $\mathbf{2 0}$ & $\mathbf{2 5}$ & \\
\hline C-29 & 0.31 & 0.51 & 0.57 & 0.00 & 0.00 & 0.00 & 0.23 \\
\hline C-35 & 0.33 & 0.51 & 0.69 & 0.00 & 0.00 & 0.00 & 0.25 \\
\hline C-40 & 0.42 & 0.58 & 0.76 & 0.00 & 0.00 & 0.00 & 0.29 \\
\hline Mean & 0.35 & 0.53 & 0.67 & 0.00 & 0.00 & 0.00 & \\
\hline & Isolate & Concentration & \multicolumn{2}{l|}{ Interaction (I*C) } \\
\hline SEM & 0.004 & 0.005 & 0.009 & \\
\hline CD $(\mathbf{5 \%})$ & 0.01 & 0.01 & 0.02 & \\
\hline
\end{tabular}

Table.7 Effect of different concentrations of poplar leaf extract on the growth of Sclerotium rolfsii

\begin{tabular}{|c|c|c|c|c|c|c|c|}
\hline \multirow{2}{*}{$\begin{array}{l}\text { Isolate } \\
\text { No. }\end{array}$} & \multicolumn{6}{|c|}{ Plant extract (\%)/Dry mycelium weight (g) } & \multirow[t]{2}{*}{ Mean } \\
\hline & Control (0) & 5 & 10 & 15 & 20 & 25 & \\
\hline S-21 & 0.70 & 0.79 & 0.00 & 0.00 & 0.00 & 0.00 & 0.25 \\
\hline S-97 & 0.69 & 0.76 & 0.00 & 0.00 & 0.00 & 0.00 & 0.24 \\
\hline S-104 & 0.53 & 0.63 & 0.00 & 0.00 & 0.00 & 0.00 & 0.19 \\
\hline \multirow[t]{2}{*}{ Mean } & 0.64 & 0.72 & 0.00 & 0.00 & 0.00 & 0.00 & \\
\hline & \multicolumn{2}{|l|}{ Isolate } & \multicolumn{2}{|c|}{ Concentration } & \multicolumn{3}{|c|}{ Interaction $\left(\mathrm{I}^{*} \mathrm{C}\right)$} \\
\hline SEM & \multicolumn{2}{|l|}{0.002} & \multicolumn{2}{|c|}{0.003} & \multicolumn{3}{|c|}{0.005} \\
\hline CD (5\%) & \multicolumn{2}{|l|}{0.01} & \multicolumn{2}{|c|}{0.01} & \multicolumn{3}{|l|}{0.02} \\
\hline
\end{tabular}

Table.8 Time of Initiation and maturation of the sclerotia of Sclerotium rolfsii in different concentrations of poplar leaf extract

\begin{tabular}{|c|c|c|c|c|}
\hline \multirow{2}{*}{ Isolate No. } & \multicolumn{3}{|c|}{ Plant extract (\%)/Initiation and maturation of sclerotia(Days) } \\
\cline { 2 - 5 } & \multicolumn{2}{|c|}{ 0 Control } & \multicolumn{2}{c|}{5} \\
\cline { 2 - 5 } & Initiation & Maturation & Initiation & Maturation \\
\hline S-21 & 7 & 10 & 10 & 15 \\
\hline S-97 & 8 & 12 & 10 & 16 \\
\hline S-104 & 7 & 11 & 9 & 15 \\
\hline
\end{tabular}


Table.9 Number of sclerotia of Sclerotium rolfsii in different concentrations of Poplar leaf extract

\begin{tabular}{|c|c|c|}
\hline \multirow{2}{*}{ Isolate No. } & \multicolumn{2}{|c|}{ Plant extract (\%)/No. of sclerotia formed } \\
\cline { 2 - 3 } & 0 Control & $\mathbf{5}$ \\
\hline S-21 & 257 & 213 \\
\hline S-97 & 293 & 252 \\
\hline S-104 & 236 & 215 \\
\hline
\end{tabular}
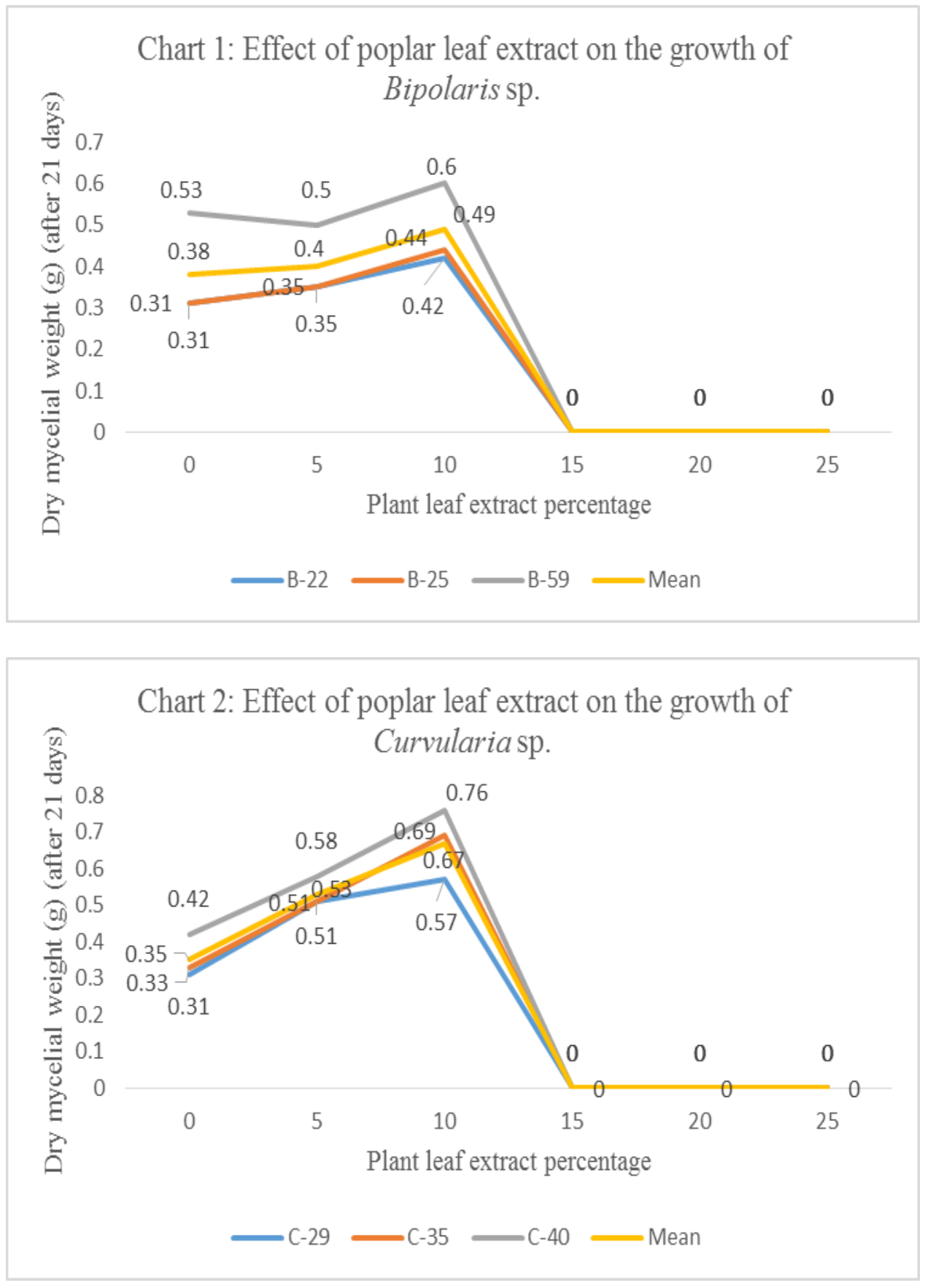

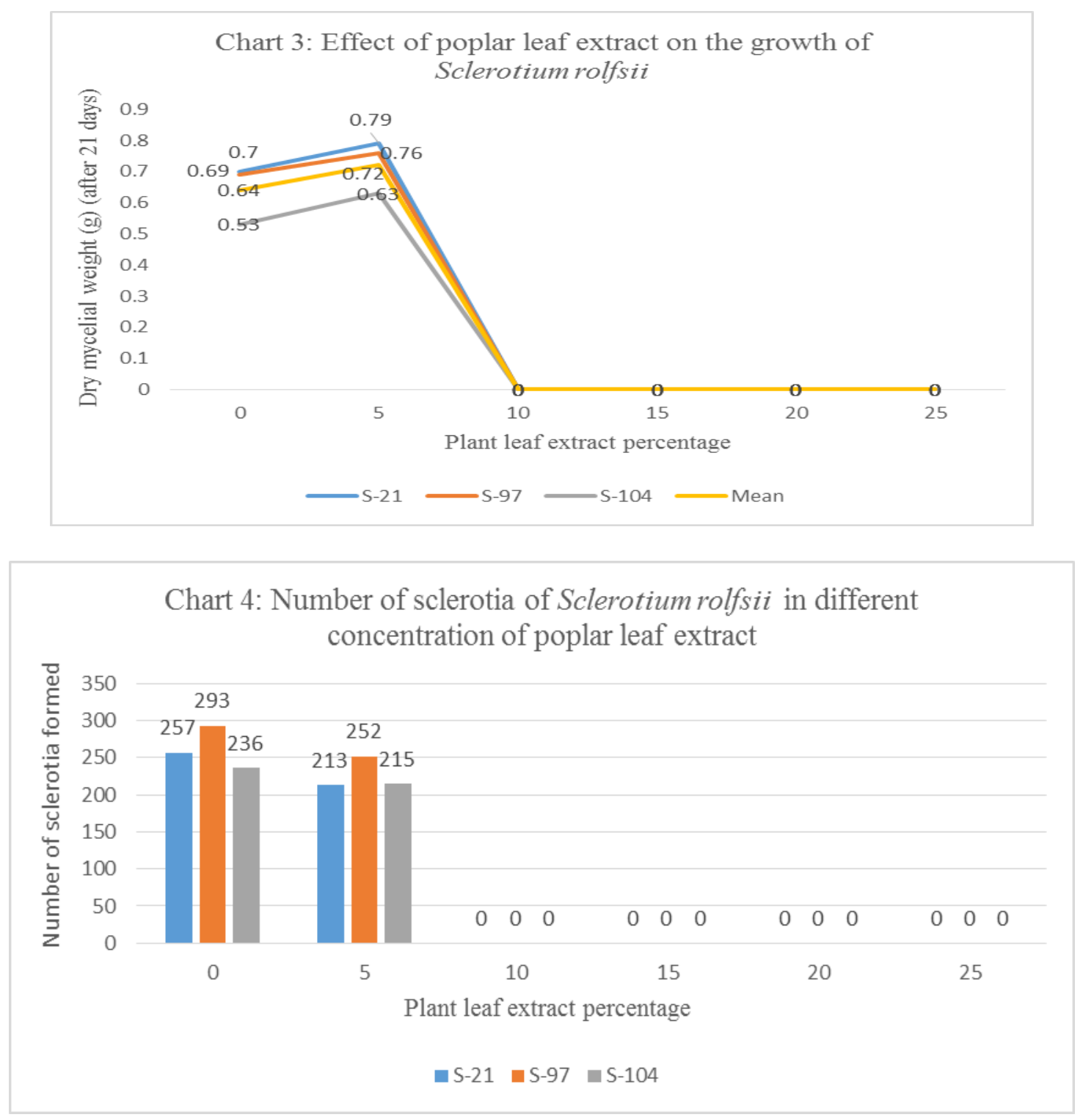

Fig.1 Growth pattern of Bipolaris sp. in different leaf extract concentration

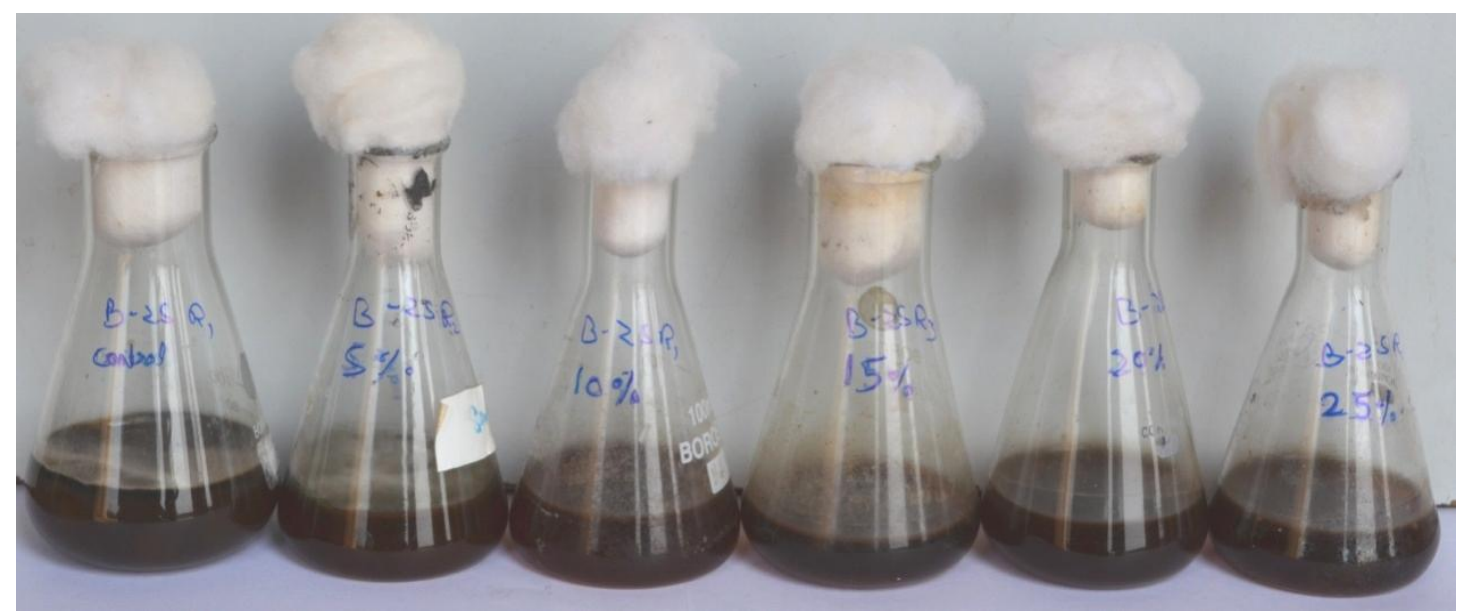


Fig.2 Growth pattern of Curvularia sp. in different leaf extract concentration

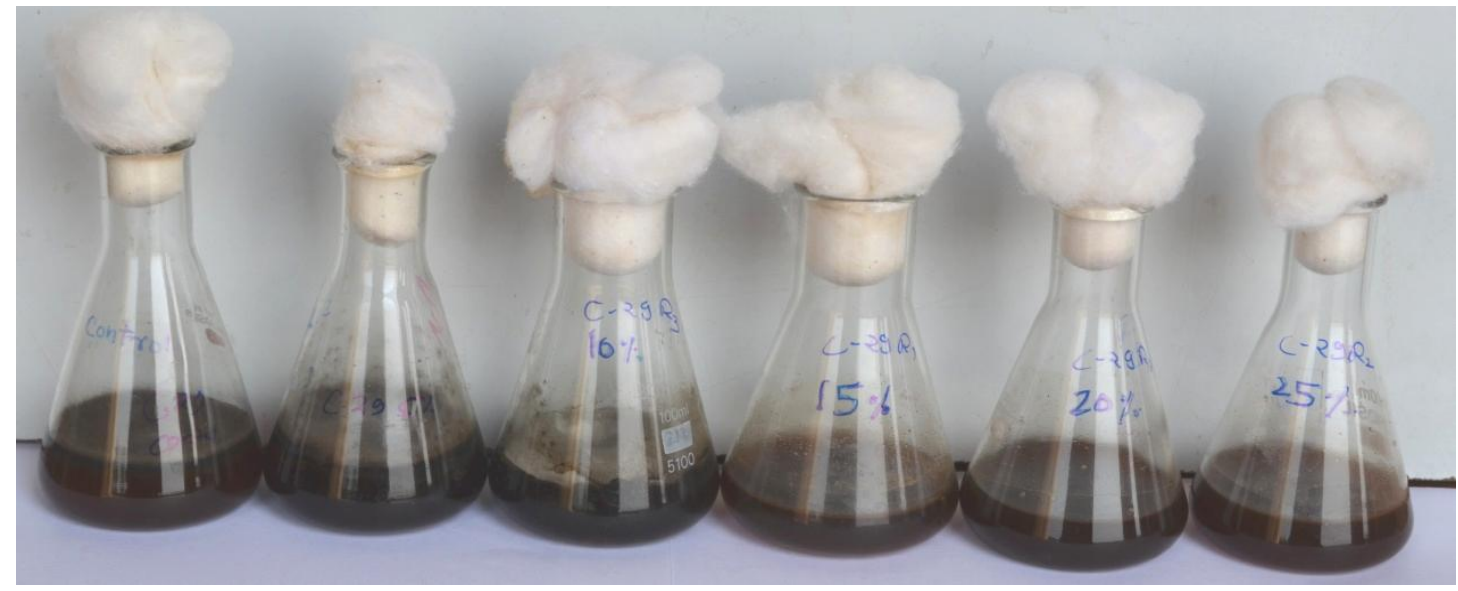

Fig.3 Growth pattern of Sclerotium rolfsii in different leaf extract concentration

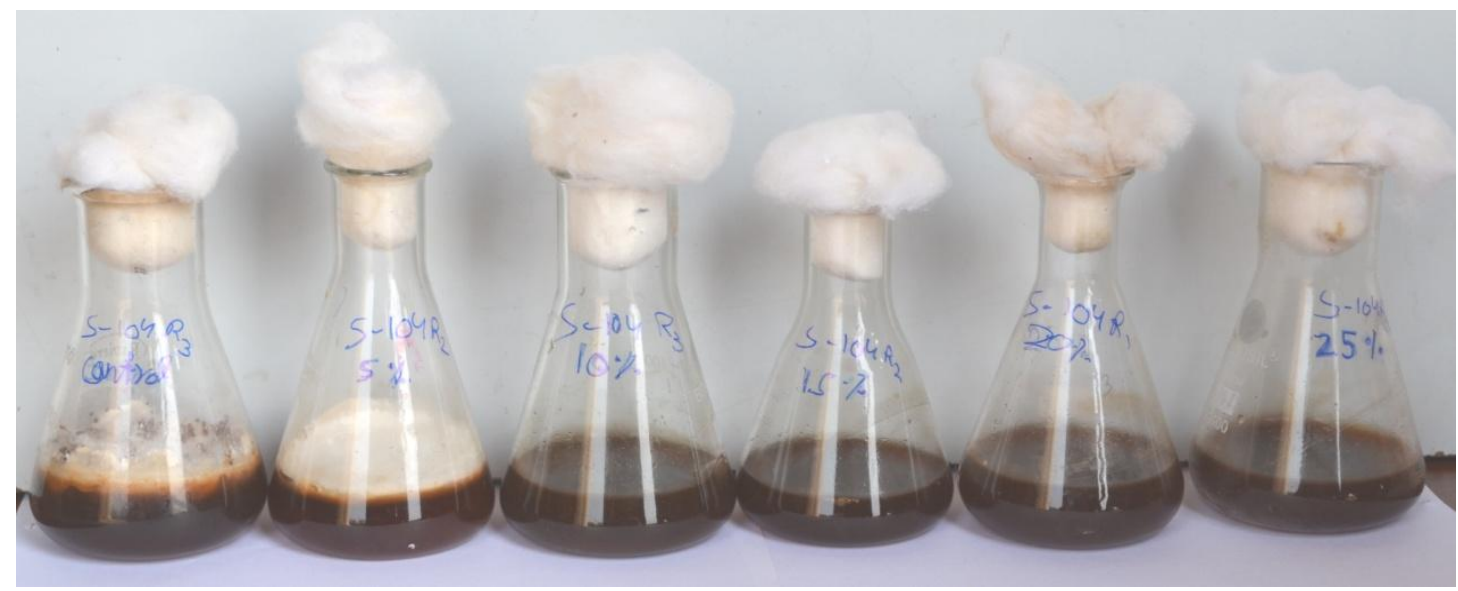

When interactions between isolate and concentrations $\left(\mathrm{I}^{*} \mathrm{C}\right)$ were studied, it was found that isolate no. C-40 $(0.76 \mathrm{~g})$ had maximum and significantly more dry mycelium weight. Minimum and significantly low dry mycelium weight was recorded by the isolate no. C-29 $(0.31 \mathrm{~g})$ on control which was at par with isolate no. C-35 on the same medium. All isolates of Curvularia sp. exhibited significantly higher growth at 5 and $10 \%$ leaf extract concentrations as comparative to control (Table 6).

Irrespective of different concentrations of poplar leaf extract tested, it was found that isolate no. S-21 $(0.25 \mathrm{~g})$ had maximum dry mycelium weight which was at par with dry mycelium weight of isolate no. S-97 $(0.24 \mathrm{~g}$; Table 7). Maximum and statistically higher dry mycelium weight was recorded at $5 \%$ leaf extract concentration when isolates were ignored while, minimum and significantly low dry mycelium weight were recorded at the control.

All the isolates of Sclerotium rolfsii showed significant and maximum dry mycelium weight at $5 \%$ leaf extract concentration when interactions between isolates and different concentration of leaf extract were $\left(\mathrm{I}^{*} \mathrm{C}\right)$ studied (Table 7). Isolate no. S-21 had significant and maximum dry mycelium 
weight $(0.79 \mathrm{~g})$ at $5 \%$ leaf extract concentration. While, minimum dry weight was recorded by the isolate no. S-104 (0.53g) on control. All the isolates at $5 \%$ leaf extract concentration had significantly higher dry mycelium weight than control.

\section{Initiation and maturation of sclerotia of Sclerotium rolfsii}

The Sclerotia of Sclerotium rolfsii isolates showed differential pattern of initiation and maturation on different poplar leaf extract concentrations (Table 8). The average initiation period of sclerotia was 7-8 days in case of control medium while in 5\% leaf extract medium it was 9-10 days. And the maturation period was 10-11 days in control medium and 15-16 days in 5\% leaf extract medium. Isolate no. S-27 and isolate no. S104 showed the minimum initiation period (i.e. 7 days) in control medium and Isolate no. S-97 showed the maximum maturation period (i.e. 16 days) in $5 \%$ leaf extract medium.

\section{Number of sclerotia formed}

In case of sclerotia formation, the maximum no. of sclerotia was formed in isolate no. S-97 in control medium (i.e. 293) and minimum no. of sclerotia were formed in isolate no. S$21 \mathrm{n} \mathrm{5 \%}$ leaf extract medium (i.e. 213). It was also seen that sclerotia formation was more in every isotopes of Sclerotium rolfsii in control medium in comparison to the 5\% leaf extract medium (Table 10).

Present study reveals the effect of the host leaf extract on the growth of its pathogens. Experiment was done with three isolates of Curvularia spp., Bipolaris spp. and Sclerotium rolfsi and came to the conclusion that although host extract medium is good for the growth of the pathogens but it is good up to a certain level after that when we used the high concentration of the leaf extract, it become poisonous to the isolates. It may be due to the fact that Plant have their own feature of resistance which is due to the biochemical present inside the plant. At higher concentration of the leaf extract this resistant chemical may become inhibitory as its concentration is also increased. This fact get support from the research evidence that some clone are resistant to the same fungus and some are less prone to the infection which is due to the quality or quantity of the resistant chemical compound present inside the host plant. Further study require in this, what chemical constituent is this? Which can control the growth of the potential pathogen and if there is any way to increase the amount of production of such compound inside the plant so that we can indirectly cure the disease by providing it resistance by itself. Because disease can only be cured by two ways. Either to give the plant, resistance from outside or let the plant too healthy that it can develop its own resistance.

\section{References}

Bangarwa, K.S., 2008. Production potential, market fluctuations and present status of exotic poplar in India. In: Poplars, willows and people's wellbeing. International Poplar Commission, $23^{\text {rd }}$ Session, Beijing, China, 27-30 October 2008. 56p.

Bradshaw, H.D., Ceulemans, R., Davis, J. and Stettler, R. 2000. Emerging model systems in plant biology: Poplar (Populus) as a model forest tree. Journal of Plant Growth Regulation, 19 (3): 306-313.

Charlton, D., McIvor, I.R., Gawith, P. and Douglas, G.B. 2007. Growing poplar and willow trees on farms. Guidelines for establishing and managing poplar and willow trees on farms. National Poplar and Willow Users Group. pp. 7-16.

Dhiman, R.C., and Gandhi, J.N. 2012. Clonal development and diversity in WIMCO's poplar programme. ENVIS Forestry Bulletin, 12 (1): 40-48.

Dickmann, D.I., and Stuart, K.W. 1983. The 
culture of poplars in eastern North America. Michigan State University, Easy Lansing, Mich., FAO For. Ser. 10p.

Eckenwalder, J.E., 1996. Systematics and evolution of Populus. In: Stettler, R.F., Bradshaw, H.D., Heilman, P.E. and Hinckley, T.M. eds. Biology of Populus: Implications for management and conservation. Ottawa, National Research Council of Canada. pp. 7-32.

Flathman, P.E., and Lanza, G.R. 1998. Phytoremediation: Current views on an emergent green technology. J. Soil Contamination, 7: 415-432.

Jain, S.K., and Singh, P. 1999. Performance of intercrops in agroforestry system: The case of poplar (Populus deltoides) in Uttar Pradesh (India). Indian Forester, 125: 195205.

Jaiswal, S.C., Mishra, V.K. and Verma, K.S. 1993. Intercropping ginger and turmeric with poplar (Populus deltoides ' $\mathrm{G}-3$ ' Marsh). Agroforestry Systems, 22: 111-117.

Kumar D., Singh N.B., Rawat G.S., Srivastava S.K. and Mohan D. 1999. Improvement of Populus deltoides Bartr. Ex Marsh in IndiaI. Present Status. Indian Forester, 125 (3): 245-263.

Mishra, A., Swamy, S.L., Bargali, S.S. and Singh, A.K. 2010. Tree growth, biomass and productivity of wheat under five promising clones of Populus deltoides in agrisilviculture system. International Journal of Ecology and Environment Science, 36 (23): 167-174.

Pande, P.K., and Dhiman, R.C. 2010. Variations in wood traits in micro- and macropropagated plantation woods of Populus deltoides Bartr. Ex Marsh. Advances in
Bioscience and Biotechnology, 1: 263-275. Pandey, P.C., and Khan, S.N. 1992. Disease status of poplars in India. In: Proceedings of XIX ${ }^{\text {th }}$ session of the FAO/International Poplar Commission. Spain, Zaragoza, September $22^{\text {nd }}-25^{\text {th }}, 1992$. pp. $1-7$.

Polle, A., and Douglas, C. 2010. The molecular physiology of poplars: Paving the way for knowledge-based biomass production. Plant Biology, 12 (2): 239-241.

Singh N.B., Kumar, D., Rawat, G.S. and Srivastava, S.K. 1999. Improvement of Populus deltoides Bartr. Ex. Marsh. in India II: Future strategy. Indian Forester, 125 (3): 341-354.

Singh, O., Sharma, D.C. and Rawat, J.K. 1993. Production and decomposition of leaf litter in Sal, Teak, Eucalypts and Poplar forests in Uttar Pradesh. Indian Forester, 119: 112- 121.

Singh, S., Khan, S.N. and Misra, B.M. 1983. Some new and note-worthy diseases of poplars in India. Indian Forester, 109 (9): 636-44.

Singh, Y.P., Uniyal, K., Bagwari, A., Kavita, Barthwal, S., Dhiman, R.C.; Gandhi, J.N. 2012.Status of poplar disease in India. ENVIS Forestry Bulletin, 12 (1): 84-99.

Tewari, D.N., 1993. Poplar. Surya Publications, Dehradun. pp. 3-19.

Zhao, S., and Shamoun, S. F. 2006. The effects of culture media, solid substrates, and relative humidity on growth, sporulation and conidial discharge of Valdensinia heterodoxa. Mycol. Res., 110(11): 13401346.

\section{How to cite this article:}

Jalaj Saxena, Vijay Vardhan Pandey and Reenu Sisodia. 2017. Evaluating Poplar Leaf Extract Concentration on Potential Plant Pathogens. Int.J.Curr.Microbiol.App.Sci. 6(9): 2933-2942. doi: https://doi.org/10.20546/ijcmas.2017.609.360 